\title{
Esophageal Cancer and Surgical Margins: When a Positive Is a Negative
}

\author{
Stephanie G. Worrell, MD \\ Case Western Reserve University and University Hospitals, Cleveland, $\mathrm{OH}$
}

Esophagectomy is a technical operation with multiple small steps that must be precisely performed. The goal of the operation is to remove all disease with an adequate lymphadenectomy and an adequate margin. The definition of "adequate" for both of these aspects is a matter of debate. Even more complicating is that proximal, radial, and distal margins need to be considered. A radial margin comprising at least $1 \mathrm{~mm}$ of microscopically normal tissue is recommended. ${ }^{1}$

The suggested proximal and distal margin lengths for esophageal cancer are well described for squamous cell carcinoma. For adenocarcinoma of the esophagus, the data regarding adequate margins are less clearly defined. In the past, a margin of 10-12 $\mathrm{cm}$ was recommended due to the risk of submucosal lymphatic spread. ${ }^{2}$ The current data from squamous cell carcinoma suggest that a minimum margin of $3.5-5 \mathrm{~cm}$ is needed to decrease the risk of local recurrence. ${ }^{3,4}$

Regardless of the margin length, a positive margin after esophagectomy is associated with worse overall survival. ${ }^{5}$ Furthermore, a positive margin may be found in the operating room or on the final pathology report. At times, a positive margin found in the operating room may be difficult to correct due to technical limitations that prevent reresection to negative margins. If a positive margin is found on the final pathology, it is often impossible to return the patient to the operating room for further resection.

\footnotetext{
(C) Society of Surgical Oncology 2020
}

First Received: 11 December 2019;

Published Online: 3 January 2020

S. G. Worrell, MD

e-mail: stephanie.worrell@uhhospitals.org
The article by Schlick et al. ${ }^{6}$ identifies within the National Cancer Database (NCDB) an overall margin positivity rate after esophagectomy over $9 \%$. This rate increases to $14 \%$ for patients 75 years of age or older. To put this in perspective, a positive surgical margin only occurs in $6.9 \%$ of patients following resection of colon and rectal cancer and in $6.6 \%$ patients following resection for lung cancer in the NCDB. ${ }^{7}$

Additional factors associated with margin positivity after esophagectomy have been described previously and highlight disparities in care, with advanced and large tumors all having higher rates of margin positivity. The main question in the article by Schlick et al. ${ }^{6}$ and in clinical practice is whether there are any modifiable risks to help decrease the shockingly high rate of margin positivity? The modifiable risk factors identified by Schlick et al. ${ }^{6}$ include the use of neoadjuvant therapy, the surgical approach, and hospital volume.

Neoadjuvant therapy is now almost universally used for all resectable patients that present with esophageal cancer. The ChemoRadiotherapy for Esophageal cancer followed by Surgery Study (CROSS) trial showed a survival benefit with the use of neoadjuvant chemotherapy and radiation before esophagectomy. The only resectable patients excluded from the CROSS trial were those with T1a/T1bN0 disease. ${ }^{8}$ Controversy still exists concerning the use of neoadjuvant therapy for patients with cT1N1 or cT2N0 disease. The use of neoadjuvant therapy to avoid a positive surgical margin should be considered when evaluating these borderline patients. If other highrisk factors are present such as high-grade differentiation, large tumor size $(>3.25 \mathrm{~cm})$, and a tumor located within the upper third of the esophagus, then the use of neoadjuvant therapy should be strongly considered. ${ }^{6,9,10}$

The surgical approach has implications for short- and long-term outcomes. Minimally invasive esophagectomy (MIE) has demonstrated superior short-term outcomes 
compared with open esophagectomy, including decreased intra- and postoperative morbidity. ${ }^{11,12}$ The decrease in postoperative morbidity is largely attributable to respiratory complications. ${ }^{11}$ In a randomized trial of MIE versus open esophagectomy, MIE was associated with decreased pulmonary complications, a shorter hospital stay, improved short-term quality of life, and non-inferiority of long-term outcomes. ${ }^{11,12}$ The use of MIE requires experience which is tied very closely to hospital volume. For MIE not to be associated with inferior margin status, adequate experience and continued volume by both the surgeon and the hospital system are required.

Esophagectomy is a key part in the multi-modality treatment of esophageal cancer. The morbidity and mortality of esophagectomy have improved during the last few decades, and now we must focus on the highest-quality oncologic outcomes. The key factors in oncologic resection are the number of resected lymph nodes and appropriate margins at the time of resection. Avoiding positive surgical margins is a key quality metric for good oncologic surgery. Surgeons must continue to use all available information and tools to continue to decrease the current rate of positive margins, which continue to result in poor long-term outcomes for esophageal cancer patients.

\section{REFERENCES}

1. Royal College of Pathologists. Dataset for the histopatholgical reporting of oesophageal and gastric carcinoma. 3rd ed. The Royal College of Pathologist, London, England, 2019.

2. Tam PC, Siu KF, Cheung HC, et al. Local recurrences after subtotal esophagectomy for squamous cell carcinoma. Ann Surg. 1987;205:189-194.
3. Chiu CH, Chao YK, Wen YW, et al. Resection margins in esophageal squamous cell carcinoma after chemoradiotherapy: predictors and prognostic significance. World $J$ Surg. 2017;41:191-9.

4. Kang $\mathrm{CH}$, Hwang Y, Lee HJ, et al. Risk factors for local recurrence and optimal length of esophagectomy in esophageal squamous cell carcinoma. Ann Thorac Surg. 2016;102:1074-80.

5. Javidfar J, Speicher PJ, Hartwig MG, et al. Impact of positive margins of survival in patients undergoing esophagogastrectomy for esophageal cancer. Ann Thorac Surg. 2016;101:1060-7.

6. Schlick CJ, Khorfan R, Odell D, et al. Margin positivity in resectable esophageal cancer: are there modifiable risk factors? Ann Surg Oncol. 2019 (in press)

7. Orosco RK, Tapia AJ, Califano JA, et al. Positive surgical margins in the 10 most common solid cancers. Sci Rep. 2018;8:5686.

8. Van Hagen P, Hulshof MCCM, van Lanschot JJB, et al. Preoperative chemoradiotherapy for esophageal or junctional cancer. $N$ Engl J Med. 2012;366:2074-84.

9. Esophageal Cancer Study Group Participating Centers. Predictors of staging accuracy, pathologic nodal involvement, and overall survival for cT2N0 carcinoma of the esophagus. J Throac Cardiovasc Surg. 2018;25:3783-4.

10. Boys JA, Worrell SG, Chandrasoma P, et al. Can the risk of lymph node metastases be gauged in endoscopically resected submucosal esophageal adenocarcinomas? A multi-center study. J Gastrointest Surg. 2016;20:6-12.

11. Mariette C, Markar SR, Dabakuyo-Yonli TS, et al. Hybrid minimally invasive esophagectomy for esophageal cancer. $N$ Engl $J$ Med. 2019;380:152-62.

12. Cuesta MA, Biere SS, van Berge Henegouwen MI, van der Peet DL. Randomised trial, Minimally Invasive Oesophagectomy versus open oesophagectomy for patients with resectable oesophageal cancerJ Thorac Dis. 2012;4:462-4

Publisher's Note Springer Nature remains neutral with regard to jurisdictional claims in published maps and institutional affiliations. 